\title{
Comparative changes in plasma concentrations of progesterone, oestradiol and LH during the ovulatory cycle in a multiple ovulating male line and a single ovulating traditional line of turkeys
}

\author{
S. Buchanan, G. W. Robertson and P. M. Hocking* \\ Roslin Institute, Roslin, Midlothian EH25 9PS, UK
}

The aim of this study was to compare the profile of circulating concentrations of $\mathrm{LH}$, progesterone and oestradiol in a multiple ovulating male line with that of a single ovulating line of traditional turkeys. Plasma samples from seven traditional and $\mathbf{1 2}$ male-line turkeys were obtained every $3 \mathrm{~h}$ for $36 \mathrm{~h}$. Male-line and traditional turkeys had single peaks of $\mathrm{LH}$ and progesterone that were of similar duration in both lines. The mean height of the plasma peaks of LH and progesterone were similar in the two lines and there was no detectable peak plasma oestrogen concentration. Mean plasma concentrations of $\mathrm{LH}$ and oestrogen were higher in single compared with multiple ovulating turkeys, whereas there were no differences in mean plasma progesterone concentrations. The results indicate that the multiple ovulation state in genetically selected high-growth lines of turkey may be the result of a correlated response in the steroidogenic capacity of ovarian tissue associated with low plasma concentrations of oestrogen rather than of a disturbance in the hormone profile of the ovulatory cycle.

\section{Introduction}

The ovarian follicular hierarchy of avian species consists normally of a single series of follicles of increasing size that will be ovulated on separate days after achieving maturity. For a turkey laying an egg each day, the ovary should contain no more than nine or ten of these hierarchical follicles (Hocking, 1987), although some turkeys will have fewer follicles and will not lay on consecutive days. In contrast to traditional turkeys, modern lines that have been genetically selected for high growth rates have relatively large ovaries with many more maturing ovarian hierarchical follicles (Hocking, 1992; Melnychuk et al., 1997). The presence of two or more follicles at each position in the hierarchy results in the ovulation of two or more follicles in a single day. Many of the eggs that result from multiple ovulations are not suitable for incubation because of the increased proportion of double-yolked, soft-shelled and misshapen eggs that are laid (Hocking and Bernard, 1998). A significant proportion of ova from multiple ovulations is not collected by the infundibulum and is lost into the body cavity, where the triglyceride they contain is absorbed (Hocking, 1996). It is not known whether multiple ovulations occur separately throughout the day or at the same time.

A preovulatory peak in LH occurs 4-8 h before ovulation in turkeys and is accompanied by an increase in the

*Correspondence

Email: paul.hocking@bbsrc.ac.uk concentration of progesterone in the plasma (Hammond et al., 1981; Sharp et al., 1981; Yang et al., 1997). Opel and Arcos (1978) measured plasma oestradiol concentrations throughout the ovulatory cycle in turkeys, but found no consistent pattern of changes in relation to ovulation. The effect of a multiple follicular hierarchy on the plasma steroid hormone profile during the ovulatory cycle has not previously been investigated in turkeys. Sharp et al. (1976) reported that there was no increase in the number of peaks in LH concentration during the ovulatory cycle of a strain of White Leghorn chickens selected for a high incidence of multiple ovulations compared with a commercial laying strain. Sharp et al. (1976) concluded that the multiple ovulations were attributable to a defect in the development of the follicular hierarchy rather than to a disturbance of the profile of circulating LH concentrations.

A comparison of the hormonal profile throughout the ovulatory cycle of turkeys that produce single or multiple ovulations has not yet been conducted. Therefore, a serial sampling experiment was performed to compare plasma oestradiol, progesterone and LH concentrations throughout the ovulatory cycle in a single ovulating traditional line and a multiple ovulating male line of turkeys. The aim of the study was to detect any differences in the plasma hormone profiles between the two strains during the ovulatory cycle, and to test the hypothesis that multiple ovulations are associated with multiple pre-ovulatory LH peaks throughout the ovulatory cycle or with a prolonged increase in $\mathrm{LH}$. Both of these situations would indicate that ovulations occur at different times throughout the day. Alternatively, if 
the pre-ovulatory $\mathrm{LH}$ peak in the male line resembled that of the single ovulating traditional line, it would imply that several follicles were ovulated together in response to a single LH peak. In spite of the excessively large quantity of ovarian tissue and hierarchical follicles in the male line, plasma oestrogen concentrations are higher in traditionalcompared with male-line hens (Buchanan et al., 1999, 2000). A second objective of the present study was to determine plasma oestrogen concentrations to assess the hypothesis that high concentrations at some point during the ovulatory cycle are responsible for the higher prevalence of vaginal prolapse in the male line, as discussed by Buchanan et al. (1999). Ideally, plasma concentrations of FSH would also have been determined but the only available avian assay (Krishnan et al., 1993) does not measure turkey FSH.

\section{Materials and Methods}

\section{Animals}

The strains of turkeys (Meleagris gallopavo) used in these experiments were the Big 6 male line, obtained from British United Turkeys Ltd (Chester) and the Nebraska Spot, a traditional line maintained at the Roslin Institute. Thirty female turkeys from each line were obtained at 1 day old and reared in floor pens containing wood shavings. They had constant access to water and were fed a conventional turkey diet provided in suspended tubular feeders. The photoperiod was $14 \mathrm{~h}$ light:10 h dark (light from 02:00 to 16:00 h) for the first 18 weeks, $7 \mathrm{~h}$ light:17 h dark for the next 11 weeks, followed by photostimulation at 29 weeks and 4 days with $14 \mathrm{~h}$ light:10 h dark to stimulate sexual maturity. At 18 weeks of age, four turkeys from each strain were housed in six pens, in a randomized block design. Individual egg production was recorded by feeding the turkeys capsules containing fat-soluble dyes three times per week. Gelatin capsules (size 4, Agar Scientific Ltd, Stansted, Essex) were half filled with Sudan black or Sudan III (red) and fed by gavage three times per week. The traditional turkeys received one capsule and the male line received two capsules because of the dilution effect of their greater body weight. Within a pen, one turkey was given black, one turkey was given red, one turkey was given alternating red and black and one bird was handled but not fed a capsule. Eggs were collected daily, boiled in a waterbath for $20 \mathrm{~min}$ and then cut in half. The colour of the dyed rings in the yolks of the eggs enabled the egg production of each hen to be determined. Within each pen, the turkeys with the most regular egg production were selected for the experiment, as they were most likely to ovulate during the sampling period. As the laying pattern of the male line was more irregular than that of the traditional line, 12 male-line and seven traditional-line turkeys were used for the experiment.

The sampling period for plasma collection started 6 weeks after the onset of photostimulation. The turkeys were handled daily in the week before the sampling period to allow them to become accustomed to handling, so that the interference caused by the sampling was less likely to delay oviposition. Whole blood was obtained from each turkey by superficial venepuncture of the brachial vein and transferred to blood collection tubes coated with $5 \mathrm{ml}$ heparin. The samples were centrifuged at $2000 \mathrm{~g}$ for $10 \mathrm{~min}$ and the plasma was removed and stored in $1.5 \mathrm{ml}$ Eppendorf tubes at $-20^{\circ} \mathrm{C}$. Each of the selected turkeys was sampled every $3 \mathrm{~h}$ for $36 \mathrm{~h}$ starting at 10:00 h. The sampling took about $1 \mathrm{~h}$ and the turkeys were always sampled in the same order to ensure a period of $3 \mathrm{~h}$ between each sample. During the hours when the lights were off, spectacle type head torches (RS Components Ltd, Corby) were used for the sampling to minimize disruption of the lighting schedule. Egg production was recorded hourly for the final $24 \mathrm{~h}$ of the sampling.

Turkeys were killed $12 \mathrm{~h}$ after the final blood sample was collected by an overdose of sodium pentobarbitone (Veterinary Drug Company, Falkirk). The abdominal cavity was opened and the ovary removed from the body cavity. Yellow ovarian follicles were cut from the residual ovary and follicles $>0.5 \mathrm{~g}$ were classed as hierarchical ovarian follicles, counted and weighed. The postovulatory follicles were removed and counted, and the residual ovary was weighed. The sequence of previous ovulations was estimated by arranging the postovulatory follicles according to size, with follicles of similar size grouped together by the same person as likely multiple ovulations. These data supplemented the egg production data and allowed comparison of the ovulation pattern to the hormone profile for each bird. The mass of the residual ovary was also recorded.

\section{Radioimmunoassays}

The plasma concentrations of oestradiol, progesterone and LH were measured by classical double antibody radioimmunoassays. Each assay was validated for use on turkey plasma by serial dilution of single samples to check for parallelism with the standard curve. Samples for each hormone were analysed in single assays to eliminate interassay variability. Oestradiol concentrations were determined in duplicate using the method of Webb et al. (1985). The plasma samples were extracted initially using an antibody-Sepharose extraction procedure because of the high fat content of laying turkey plasma. The efficiency of the extraction procedure was $45.7 \%$. The mean intra-assay coefficient of variation was $15.2 \%$ and the lowest sensitivity of the assay was $1.5 \mathrm{pg}$ per tube. The concentration of progesterone was measured in duplicate as described by Law et al. (1992). The samples were analysed in a single assay with an intra-assay coefficient of variation of $12.1 \%$ and lowest sensitivity of $25 \mathrm{pg}$ per tube. The plasma concentration of $\mathrm{LH}$ was determined in triplicate as described by Sharp et al. (1987). The intra-assay coefficient of variation was $12.3 \%$ and the lowest sensitivity of the assay was $0.045 \mathrm{ng}$ per tube. 
Table 1. Mean ( \pm SEM) number of postovulatory follicles and number of postovulatory follicles of the largest size in traditional line $(n=7)$ and male line turkeys $(n=12)$

\begin{tabular}{lccc}
\hline Postovulatory follicles & Traditional line & Male line & Significance \\
\hline Number & $3.1 \pm 0.34$ & $7.9 \pm 1.15$ & $P<0.01$ \\
Largest (similar size) & $1.0 \pm 0.00$ & $2.0 \pm 0.19$ & $P<0.001$ \\
\hline
\end{tabular}

\section{Statistical analyses}

Two-sample unpaired Student's $t$ tests were used to compare the mean hormone concentrations over the sampling period and the ovarian characteristics for each strain. The height of the peak in hormone concentration was calculated as the difference between the highest concentration and an average baseline value for each bird. The duration of each peak was estimated as the difference in sample time from the start of the steep increase in concentration to the time when the concentration had returned to baseline values. The mean height and duration of the peaks in progesterone and LH were compared using two-sample unpaired Student's $t$ tests. A one-sample $t$ test was used to test whether the time difference between the peak in progesterone and the peak in $\mathrm{LH}$ was significantly different from zero, and a two-sample $t$ test was used to compare the time difference between the two lines of turkeys.

\section{Results}

Eggs were obtained from five of the seven traditional-line and four of the 12 male-line turkeys during the sampling period. Postmortem examination of the records of eggs laid after the sampling period and the presence of ovulated follicles in the oviduct when the birds were killed indicated that all of the traditional-line and nine of the 12 male-line turkeys had ovulated during the sampling period.

The male line had significantly more postovulatory follicles than did the traditional line (Table 1). Male-line turkeys also had a significantly greater incidence of two or more postovulatory follicles at the largest position (Table 1).

Typical traces of the changes in plasma oestradiol, progesterone and $\mathrm{LH}$ throughout a $36 \mathrm{~h}$ period in a traditional-line and a male-line turkey that had ovulated during the sampling period are shown (Fig. 1a,b). Plasma $\mathrm{LH}$ peaks were clearly visible in ten of the male-line and all of the traditional-line turkeys. One of the male-line turkeys showed a distinct LH peak, although no ovulated follicles were present in the oviduct (Fig. 1c) and two male-line turkeys showed no evidence of a peak for any of the plasma hormones measured (Fig. 1d).

No turkey from either strain showed more than one peak in the plasma concentration of LH during the sampling period. The mean height and duration of the peak and the
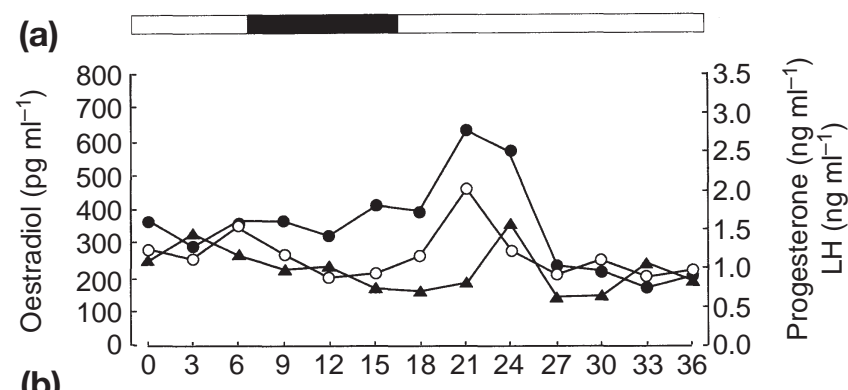

(b)

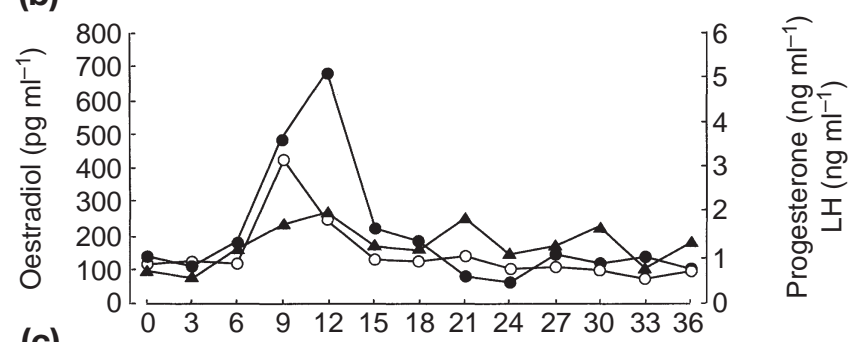

(c)
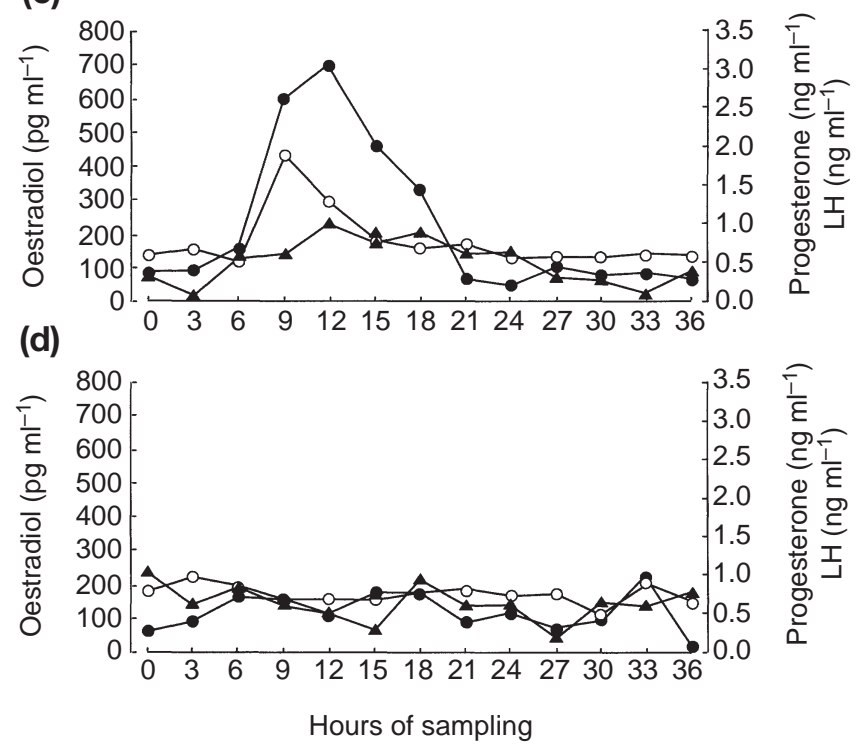

Fig. 1. Changes in plasma concentration of oestradiol $(\mathbf{\Delta})$, progesterone $(0)$ and $\mathrm{LH}(\mathrm{O})$ at $3 \mathrm{~h}$ intervals during a $36 \mathrm{~h}$ sampling period in turkeys. (a) Traditional-line turkey that ovulated during the sampling period. (b) Male-line turkey with a recorded ovulation. (c) Male-line turkey in which no oviposition was recorded and an internal ovulation is assumed to have occurred. (d) Male-line turkey in which there was no evidence for oviposition or ovulation. Bar at the top of the figure represents the photoperiod (open) and scotoperiod (filled). 

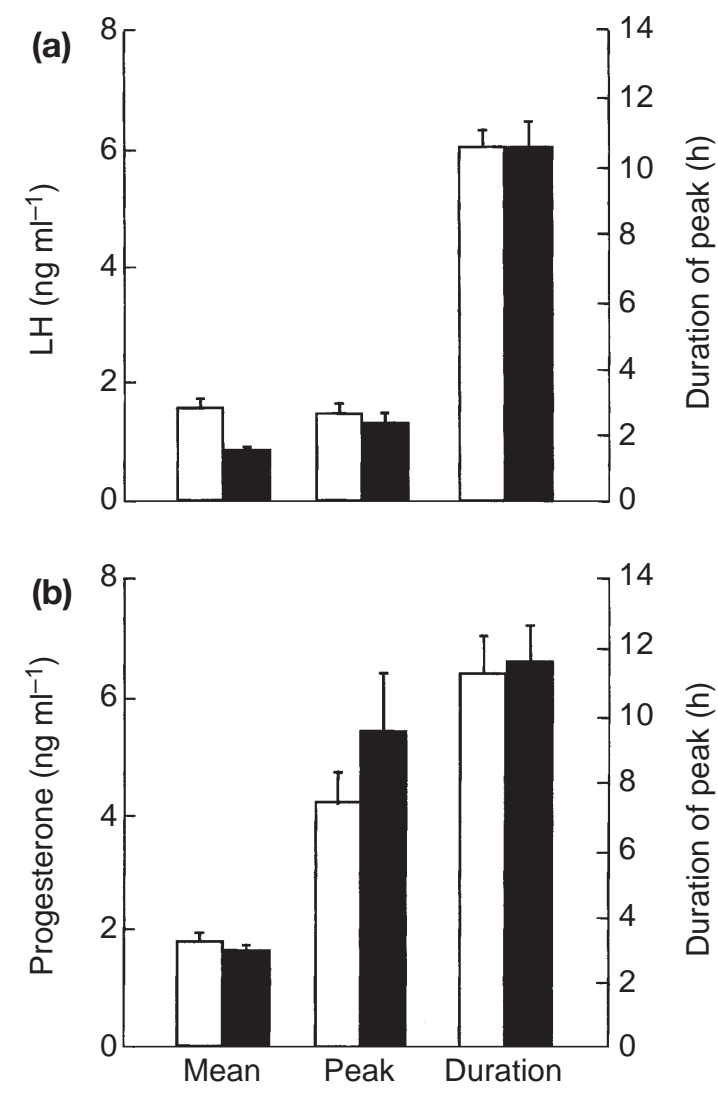

Fig. 2. Mean ( \pm SEM) plasma concentration, mean height of preovulatory peak and mean duration of the peak plasma concentration of (a) LH and (b) progesterone in traditional-line $(\square ; n=7)$ and male-line $(\boldsymbol{\square} ; n=12)$ turkeys sampled every $3 \mathrm{~h}$ for $36 \mathrm{~h}$.

overall mean plasma concentration of $\mathrm{LH}$ for the two strains are shown (Fig. 2a). The mean plasma LH concentration was significantly greater in the traditional line than in the male line $(P<0.001)$, whereas there were no differences in the mean height or duration of the $\mathrm{LH}$ peaks between the two strains.

Plasma progesterone concentration showed a preovulatory increase that coincided with the increase in plasma LH in both the traditional- and male-line turkeys (Fig. 1a,b). No such increase was visible in either of the male-line turkeys that did not ovulate during the sampling period (Fig. 1d). Progesterone concentrations reached a peak significantly later than LH concentrations $(2.0 \pm 0.5 \mathrm{~h}$, $P<0.001$ ) but there was no difference in this time period between the two strains. There was no significant difference in the duration of the progesterone peak between the two strains (Fig. 2b). The progesterone peak lasted slightly longer than the LH peak in both strains, but this difference was not statistically significant. The mean plasma progesterone concentration and mean height of the progesterone peak in the traditional- and male-line turkeys are also presented (Fig. 2b): neither the mean plasma concentration (a)

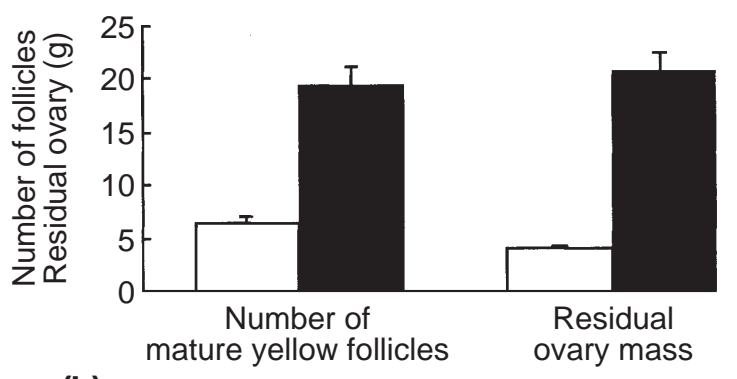

(b)

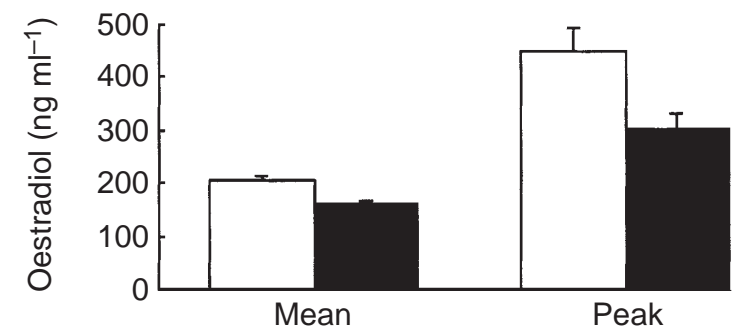

Fig 3. Plasma oestradiol concentrations, ovary mass and number of follicles in traditional-line $(\square ; n=7)$ and male-line $(\mathbf{\square} ; n=12)$ turkeys. (a) Mean ( \pm SEM) number of hierarchical follicles and residual ovary mass $12 \mathrm{~h}$ after the end of a $36 \mathrm{~h}$ sampling period. (b) Mean ( \pm SEM) plasma concentration and mean maximum concentration of oestradiol sampled every $3 \mathrm{~h}$ for $36 \mathrm{~h}$.

nor the mean plasma peak of progesterone were significantly different between the traditional and male lines.

There was no consistent pattern of changes in plasma oestradiol concentration in either the traditional- or the male-line turkeys. Some individuals showed peaks in plasma oestradiol around the same time as the LH peak (Fig. 1a,b), in others peaks occurred before or after the LH peak and in some there was no distinct oestradiol peak. The mean plasma oestradiol concentration was significantly lower in the male line compared with the traditional line $(P<0.001)$, as was the mean of the highest concentrations $(P<0.05)$ (Fig. 3b).

The male line had significantly more hierarchical follicles $(P<0.001)$ and a significantly greater residual ovary mass $(P<0.001)$ compared with the traditional line (Fig. 3a).

\section{Discussion}

The data from the $36 \mathrm{~h}$ sampling period showed peaks in plasma progesterone and $\mathrm{LH}$ associated with ovulation in both traditional- and male-line turkeys. These findings are in agreement with previous findings in turkeys (Hammond et al., 1981; Sharp et al., 1981) and domestic hens (Etches, 1996a). The lack of consistent patterns of oestradiol concentrations during the ovulatory cycle in either strain of turkey is also in agreement with previous results (Opel and Arcos, 1978).

The $\mathrm{LH}$ peaks were no more frequent in the male line 
than they were in the traditional line, indicating that multiple follicles are ovulated in response to single preovulatory peaks of $\mathrm{LH}$ and progesterone. This finding is similar to those reported by Sharp et al. (1976) that multiple ovulations occurred in the domestic hens after single LH peaks.

Multiple ovulations occurred in the male line during the sampling period as indicated by the presence of two or more fresh postovulatory follicles, although these were not necessarily associated with yolks in the oviduct or in laid eggs. The abdominal cavity of male-line turkeys frequently contained intact ovulated follicles or yolky fluid that was assumed to have come from ova that were being absorbed. The results indicate that a significant proportion of ovulated follicles is lost as internal ovulations into the abdominal cavity in male-line turkeys. No more than one egg was collected from each turkey during the $36 \mathrm{~h}$ period, confirming that the additional postovulatory follicles in the male line must represent follicles lost through internal ovulation or eggs with defective shells that were destroyed before they could be collected.

Most of the eggs laid during the sampling period contained yolks that were ovulated before the start of the sampling period and it was not possible to calculate the time between ovulation and subsequent oviposition. In general, the results did not show a clear relationship between oviposition and ovulation, such as occurs in fowl (Etches, 1996a), in which ovulation tends to occur 30-45 min after oviposition of the previous egg. A longer period of recording egg production after the sampling period would be necessary to determine the time interval between ovulation and oviposition. In the present study, it was necessary to record the presence of fresh postovulatory follicles to establish whether ovulation had occurred and a longer egg collection period was not possible.

The presence of gaps in the hierarchy corresponding to days when no follicle was recruited is more common in male-line than it is in traditional-line turkeys (Hocking and Bernard, 1998). The fact that such a gap was not observed in traditional-line turkeys in the present study may be coincidental or a consequence of prior selection for regular oviposition. The absence of peaks for $\mathrm{LH}$ and progesterone in ovulatory cycles without an observed or inferred ovulation is consistent with the conclusion that follicular growth and recruitment occur normally in multiple ovulating birds but that more than one follicle is likely to be recruited in any one period.

The peaks in plasma progesterone and LH were no more prolonged in the male line than they were in the traditional line, which further supports the hypothesis that several follicles are released in response to a single $\mathrm{LH}$ surge in the multiple ovulating strain. It seems likely that these follicles are released around the same time, relative to the time of peak plasma LH concentration. If the follicles were ovulated many hours apart, several peaks or an extended increase in LH might have been observed in a multiple ovulating line. The release of several follicles from the ovary at a similar time during the ovulatory cycle may make it difficult for the infundibulum to capture all of the follicles that are ovulated. If the oviduct did capture more than one follicle, this is likely to lead to the formation of double-yolked, misshapen or soft-shelled eggs (van Middelkoop, 1971; Hocking et al., 1987).

There was no clear pattern of changes in plasma oestradiol concentration throughout the ovulatory cycle in turkeys. The results did not provide any evidence for higher peak oestradiol concentrations in the male line than in the traditional line. When the mean plasma oestradiol concentration over the $36 \mathrm{~h}$ sampling period was compared between the two strains, plasma oestradiol was lower in the male line, confirming earlier reports of single-point estimates (Buchanan et al., 1999, 2000).

The present results showed that plasma LH was lower in the multiple ovulating male line of turkeys, in contrast to the absence of differences in the mean plasma concentrations of $\mathrm{LH}$ between single and multiple ovulating groups of domestic hens (Sharp et al., 1976). Williams et al. (1986) reported a significant difference in plasma LH concentration between fat-line and lean-line chickens, with a greater LH concentration in the lean line. It is unclear why selection for different body traits, such as increased abdominal fat or increased growth rates, should alter plasma LH concentration. It is possible that the capacities of the hypothalamus or pituitary of male-line turkeys have not increased to produce circulating plasma hormones in proportion to the increased body size of the strain. Alternatively, differential sensitivity of the hypothalamus and pituitary to stimulatory or inhibitory signals may be involved. Food restriction changes the sensitivity of the pituitary to $\mathrm{CLH}$-releasing hormone I, and possibly gonadal hormones, during the laying period (Bruggeman et al., 1998), and genetic changes associated with selection for growth rate and body composition might have had a similar effect.

No differences were found in the mean progesterone concentrations over the $36 \mathrm{~h}$ sampling period between the two strains, consistent with results obtained at a single time point (Buchanan et al., 1999, 2000). In both strains, progesterone increased to two to four times its basal concentration in a preovulatory peak that occurred slightly later than the preovulatory $\mathrm{LH}$ peak. This finding is consistent with that of Sharp et al. (1981) who showed that there was a progesterone peak about $4 \mathrm{~h}$ after $\mathrm{LH}$ in the domestic fowl. A more frequent sampling regimen would be required to determine whether the duration of increased progesterone concentration is significantly longer than the duration of increased plasma LH concentration.

From studies in domestic hens, it is thought that the onset of the preovulatory surge of progesterone stimulates the release of $\mathrm{LH}$ from the hypothalamus in a positive feedback mechanism that eventually results in ovulation, which is followed by a decrease in the release of $\mathrm{LH}$ as a result of negative feedback from high plasma steroid concentrations (Etches, 1996b). The ovary is the major source of progesterone and oestradiol: the largest follicles produce 
progesterone whereas the smaller follicles and residual ovary produce predominately oestrogens (Armstrong, 1984; Porter et al., 1991; Buchanan et al., 2001). Therefore, it was surprising that the male-line turkeys, which have many more mature follicles and a much bigger residual ovary, do not have higher plasma concentrations of progesterone and oestradiol compared with the traditional line. The results indicate that the steroidogenic capacity of the ovarian cells in the large ovary of the male line may be poor and are consistent with studies of individual ovarian follicles in vivo (Buchanan et al., 2001). Poor synthesis of oestrogen by the ovarian cells resulting in a decrease in plasma hormone concentration may affect the sensitivity of the hypothalamus and anterior pituitary, resulting in increased FSH secretion, overstimulation of ovarian growth and increased recruitment into the follicular hierarchy. The presence of lower plasma LH concentrations in the male line is consistent with this hypothesis. Alternatively, it is possible that several follicles of the largest size are required to produce sufficient progesterone to trigger ovulation in the male line. If this were the case, then genetic selection may have inadvertently resulted in the development of the typical multiple follicular hierarchy via selective breeding from females with two or more mature follicles that collectively produced enough progesterone to cause ovulation in birds with decreased sensitivity of the hypothalamus to gonadal steroids. Genetic selection for high growth rates and meat yields in turkeys may have led to an increase in the propensity for multiple ovulation by at least two routes: firstly, by overstimulation of ovarian growth as a result of a lack of control by negative feedback of oestrogens (the peripheral, or decreased gonadal steroid hypothesis) and, secondly, by requiring the progesterone output of several follicles for ovulation to occur (the central, or decreased hypothalamus-pituitary sensitivity hypothesis). However, genetic selection may act primarily through changes in local growth factor expression in the ovary, hypothalamus and pituitary that result in altered sensitivity of these tissues to regulatory signals, as has been well documented for the insulin-like growth factor (IGF) system (Lackey et al., 1999).

In summary, male-line turkeys that are characterized by multiple ovulations do not ovulate in response to multiple or extended peaks in the plasma concentrations of LH or progesterone. There was no difference in the height of the plasma peaks in LH between male-line and traditional-line turkeys, whereas the mean plasma concentration of LH was higher in traditional- than it was in male-line turkeys. The mean plasma peaks and the overall mean plasma concentrations of progesterone for the two lines were not significantly different. There was no detectable peak in plasma oestrogen concentration during the ovulatory cycle, and the mean plasma concentration of oestrogen was lower in male-line than it was in traditional-line turkeys. The multiple ovulation state in genetically selected high-growth lines of turkeys may be caused by a correlated response in the steroidogenic capacity of ovarian tissue associated with low plasma concentrations of oestrogen and a change in the sensitivity of the hypothalamus-pituitary axis.

This work was funded by a CASE studentship from the Ministry of Agriculture, Fisheries and Food and British United Turkeys Ltd. Male-line turkey poults were kindly donated by British United Turkeys Ltd, Chester. Thanks are due to Gerry Baxter and Richard Talbot for help with radioimmunoassays. The authors also acknowledge helpful discussions with Elaine Watson.

\section{References}

Armstrong DG (1984) Ovarian aromatase activity in the domestic fowl (Gallus domesticus) Journal of Endocrinology 100 81-86

Bruggeman V, Onagbesen O, Vanmontfort D, Berghman L, Verhoeven G and Decuypere $\mathbf{E}$ (1998) Effects of long-term food restriction on pituitary sensitivity to CLHRH-1in broiler breeder females Journal of Reproduction and Fertility $114267-276$

Buchanan S, Robertson GW and Hocking PM (1999) The relationships between vaginal collagen, plasma oestradiol and uterine prolapse in turkeys Research in Veterinary Science 67 153-157

Buchanan S, Robertson GW and Hocking PM (2000) Effects of food restriction or delayed photostimulation on ovarian follicle number, plasma oestradiol concentration and vaginal collagen content in maleline turkeys British Poultry Science 41 502-507

Buchanan S, Robertson GW and Hocking PM (2001) Ovarian steroid hormone production in a multiple ovulating male-line and a single ovulating traditional-line of turkeys Reproduction 121 277-285

Etches RJ (1996a) Management of reproduction using photoschedules. In Reproduction in Poultry pp 263-278 CAB International, Oxon

Etches RJ (1996b) The Ovary. In Reproduction in Poultry pp 125-165 CAB International, Oxford

Hammond RW, Burke WH and Hertelendy F (1981) Influence of follicular maturation on progesterone release in chicken cells in response to turkey and ovine gonadotrophins Biology of Reproduction 24 1048-1055

Hocking PM (1987) Observations on the size of the follicular hierarchy in the turkey hen and a case of arrested follicular growth British Poultry Science 28 755-757

Hocking PM (1992) Genetic and environmental control of ovarian function in turkeys at sexual maturity British Poultry Science 33 437-448

Hocking PM (1996) Role of body weight and food intake after photostimulation on ovarian function at first egg in broiler breeder females British Poultry Science 37 841-851

Hocking PM and Bernard R (1998) Comparative development of the ovary and production, fertility and hatchability of eggs from traditional turkeys and a contemporary male-line fed ad libitum or restricted British Poultry Science 39 291-297

Hocking PM, Waddington D, Walker MA and Gilbert AB (1987) Ovarian follicular structure of White Leghorns fed ad libitum and dwarf and normal broiler breeders fed ad libitum or restricted to point of lay British Poultry Science 28 493-506

Krishnan KA, Proudman JA, Bolt DJ and Bahr JM (1993) Development of an homologous radioimmunoassay for chicken follicle-stimulating hormone and measurement of plasma FSH during the ovulatory cycle Comparative Biochemistry and Physiology 108 253-264

Lackey BR, Gray SL and Henricks DM (1999) The insulin-like growth factor (IGF) system and gonadotropin regulation: actions and interactions Cytokine and Growth Factor Reviews 10 201-217

Law AS, Baxter G, Logue DN, O'Shea T and Webb R (1992) Evidence for the action of bovine follicular fluid factor(s) other than inhibin in suppressing follicular development and delaying oestrus in heifers Journal of Reproduction and Fertility 96 603-616

Melnychuk VL, Robinson FE, Renema RA, Hardin RT, Emmerson DA and Bagley LG (1997) Carcass traits and reproductive development at the onset of lay in two lines of female turkeys Poultry Science $\mathbf{7 6}$ 1197-1204 
Opel H and Arcos M (1978) Plasma concentration of progesterone and estradiol during the ovulatory cycle of the turkey Poultry Science $\mathbf{5 7}$ 251-260

Porter TE, Silsby JL, Behnke EJ, Knapp TR and ElHalawani ME (1991) Ovarian steroid production in vitro during gonadal regression in the turkey I. Changes associated with incubation behaviour Biology of Reproduction 45 581-586

Sharp PJ, Beuving G and van Middlekoop JH (1976) Plasma luteinizing hormone and ovarian structure in multiple ovulating hens, 5th European Poultry Conference pp 1259-1267

Sharp PJ, Lea RW, Chadwick A and Lake PE (1981) Concentrations of plasma luteinising hormone, prolactin, progesterone and androgens during the ovulatory cycle of the turkey British Poultry Science 22 375-383

Sharp PJ, Dunn IC and Talbot RT (1987) Sex differences in the LH responses to chicken LHRH-I and II in the domestic fowl Journal of Endocrinology $115323-331$

van Middelkoop JH (1971) Shell abnormalities due to the presence of two eggs in the shell gland Archiv fur Geflugelkunde 35 122-127
Webb R, Baxter G, McBride D, Nordblom GD and Shaw MPK (1985) The measurement of testosterone and oestradiol- $17 \beta$ using iodinated tracers and incorporating an affinity chromatography extraction procedure Journal of Steroid Biochemistry 23 1043-1051

Williams J, Harvey S and Leclercq B (1986) Plasma levels of luteinizing hormone, growth hormone, and estradiol from six weeks of age to sexual maturity in two lines of chickens selected for low or high abdominal fat content Poultry Science 65 1782-1786

Yang J, Long DW and Bacon WL (1997) Changes in plasma concentrations of luteinizing hormone, progesterone, and testosterone in turkey hens during the ovulatory cycle General and Comparative Endocrinology 106 281-292

Received 22 March 2001.

First decision 22 May 2001.

Revised manuscript received 31 August 2001.

Accepted 27 September 2001. 